Research into Second Language Anxiety (SLA) has largely focused on secondlanguage learners rather than immigrants. However, living in an environment where the target language (TL) is the language of everyday communication may constitute a significant source of anxiety that generalises beyond the language classroom (Pappamihiel, 2001; Rose, 2008, Woodrow, 2006). This study explored SLA across different social contexts in a sample of 190 adult immigrants from Latin America to Australia who spoke Spanish as their first language (L1) and English as their second language (L2). The aims were to (a) investigate the presence and severity of SLA among L2 long-term immigrants, and (b) examine sources of individual differences in SLA. Results indicated that SLA exists among L2 immigrants at moderate, high and very high levels, and that levels of anxiety vary significantly across social contexts. Self-perceived L2 proficiency was found to be the strongest predictor of SLA followed by extroversion and age, with higher scores on all three variables associated with lower SLA. Gender, education level, duration of residency in Australia, and emotional stability did not predict SLA in any of the contexts. These findings suggest that SLA is a significant problem for adult immigrants, permeating most aspects of their everyday lives. Practical implications and recommendations for future research are discussed.

Key words: anxiety, second language, foreign language, bilingualism, immigrant

\title{
Acknowledgments:
}

The authors would like to acknowledge Mr Alex Sentana from New South Wales

Spanish and Latin American Association for Social Assistance for his support and contribution to this project. 


\section{Second Language Anxiety among Latino American immigrants in Australia}

\section{Introduction}

Second language anxiety (SLA) refers to the specific anxiety (emotional, cognitive and physiological symptoms) arising from the process of learning and communicating in a second or foreign language. It is considered to be a situation-specific-type anxiety uniquely provoked by using a less dominant language (L2) and not simply a case of general anxiety transferred to the language classroom or to bilingual situations (Horwitz, Horwitz and Cope, 1986).

To date, research into SLA has focused on high school and university students learning a second language as part of their curriculum or for cultural, educational, or commercial reasons (Horwitz, 2010). In contrast, there has been no systematic investigation of SLA among immigrants, despite the fact that they constitute a large part of the permanent bilingual population and must function in their less dominant language on a daily basis to survive psychologically, socially, and economically (Imberti, 2007; Rose, 2008). However, it has been reported through case studies and clinical observations that many adult immigrants suffer from anxiety specifically related to communicating in their less dominant language (e.g., De Zuleta, 1990; Imberty, 2007; Bigdali, 2007) and as a result, communicate less (Noels, Pon and Clement, 1996), use fewer social, medical, and mental health services, and tend to isolate themselves (Griffith and Villavicencio, 1985; Jones Diaz, 2003). These findings highlight the need for more information regarding the extent and nature of SLA in adult L2 immigrants.

The purpose of the present study was to systematically investigate SLA among adult immigrants and to contribute to the limited body of evidence on this topic. This 
investigation is based on theory and research in the field of applied linguistics (language learning), where most findings on SLA have been generated.

\section{Second and Foreign Language Learning Anxiety}

Linguists distinguish between second language (SL) - when the target language is also the majority language (e.g., Spanish person learning English in Australia) and foreign language (FL) - when the target language differs from the local language (e.g., Spanish person learning English in Spain) (Perez-Firmat, 2003). Following this classification, anxiety is investigated as Second Language anxiety (SLA) or Foreign Language anxiety (FLA) depending on the context where the anxiety is experienced. In the present report, the expression SLA/FLA will be used except when specifically referring to FLA experienced by students in the classroom or to SLA experienced outside the classroom or by immigrants.

Anxiety related to learning a FL/SL can have debilitating effects and has been identified as one of the most important predictors of language learning and performance (Zhang and Zhong, 2012). Importantly, students who are generally calm in classroom situations may still feel anxious when learning an L2 (MacIntyre, 1995; Horwitz et al., 1986). FLA/SLA is said to stem from threats to the person's selfconcept as a 'competent communicator, intelligent, socially-adept individual, sensitive to different socio-cultural mores' (Horwitz et al., 1986, p.146).

Communicating in a less dominant language may involve both internal and external threats. Internally, adult L2 users are aware of their linguistic limitations and the discrepancies between their L1 and L2 communication capabilities (Rose, 2008). For instance, they may have sophisticated thoughts and ideas or humour they want to share, but a less sophisticated L2 vocabulary in which to express them (Bialystok, 2008; MacIntyre and Gardner, 1991). Externally, they may perceive others to be 
critical, and fear being perceived as unintelligent, uninteresting, or incompetent when they have difficulties in communicating in their L2 (Rose, 2008). This inability to accurately represent themselves in social interactions in L2 may 'challenge the individual's self-concept and perception of authenticity leading to reticence, selfconsciousness, and anxiety' (Horwitz, 1986, p.128).

Foreign and second language anxiety have been found to be negatively linked to language course final grades (Horwitz, 1986; 2001), vocabulary production (MacIntyre and Gardner, 1991), quantity and quality of speech production (Steinberg and Horwitz, 1986), willingness to use the L2 when the opportunity arises (MacIntyre, Dornyei, Clement, and Noels, 1998), self-ratings of L2 proficiency (MacIntyre, Noels, and Clement, 1997), and oral performance (Woodrow, 2006).

Research into FLA has been extended to SLA, indicating that living in an environment where the target language is also the language of everyday communication generates anxiety beyond the language classroom. Interaction with native speakers, such as interactions in the mainstream classroom, during breaks, with school personnel or outside school, is rated as the most anxiety provoking activity by second language learners (Pappamihiel, 2001; Rose, 2008; Woodrow, 2006) and many students avoid these interactions, withdrawing from peers and remaining silent in class, in order to cope with anxiety. These findings highlight the linguistic power imbalance and the loss of control over socio-cultural and linguistic parameters for peer relations that students experience when learning the target language away from home (Pappamihiel, 2001).

Dewaele, Petride, and Furham (2008) reported the first study investigating the SLA of adult L2 users in the community. Participants $(n=464)$ were adult multilinguals, highly educated and working in a language-related profession (e.g., 
translators), who indicated high levels of L2 self-reported proficiency. Participants' SLA was assessed in five different social contexts such as on the phone or at work. Sources of individual variation in SLA were also investigated by examining the effects of trait emotional intelligence (EI) and socio-biographical variables on SLA. Participants reported significantly higher anxiety when speaking in their L2 compared to L1 across all contexts, except when speaking with friends. Marked individual differences emerged, indicating that SLA was lower for participants who were (a) higher in EI, (b) reported higher L2 competence, and (c) were older. However, there were no significant effects of sex and education level on SLA. It must be noted that this was a highly specific sample (i.e., people working in language related professions) and it is unclear whether they were immigrants or not; caution is needed when applying these findings to immigrant populations.

Nevertheless, it is clear that SLA may pose a significant problem for adult bilinguals past the L2 learning stage, even for those who are highly fluent. Arguably, the experience of the adult L2 immigrant is close to the experience of the second language learner, with the potential for SLA extending beyond the fifty-minute language class and examinations into most other transactions of everyday life, includingwork, doctor visits, and shopping. This makes the exposure to the anxiety provoking stimulus (i.e., communication in L2) more constant (Rose, 2008).

Continuing interaction with native speakers further stresses the inequality in the linguistic status of the interlocutor (Ceroz, 2008). For the L2 immigrant, 'linguistic competence' goes beyond phonology, morphology, and lexicon to require sociocultural competence, and a social or cultural error in communication can be far more anxiety provoking than a linguistic error in the language classroom (Ceroz, 2008). 
Individual Differences in Foreign and Second Language Anxiety (FLA/SLA)

Individuals' reactions to language learning can vary widely; while some students experience intense anxiety, others experience moderate anxiety or no anxiety at all (Horwitz, 2001). One obvious factor affecting FSL/SLA is an individual's selfperceived competence in speaking their L2 (Donovan and MacIntyre, 2005;

Dewaele, 2008), which tends to be a good predictor of actual proficiency (MacIntyre, et al., 1997; Noels and Clement, 1996). There is also evidence that FLA/SLA is related to age, with anxiety diminishing as age increases (Onwuegbuzie, Bailey, and Daley, 1999). In contrast, levels of education (Dewaele et al., 2008) appear to be unrelated to FLA/SLA and the evidence supporting the relationship between gender and FLA/SLA is inconclusive. For instance, while Dewaele $(2002,2007)$ found no gender difference, Abu-Rabia (2010) and Dewaele and MacIntyre (2014) found that female participants reported higher FLA/SLA.

Recently, some researchers have begun to explore the impact of personality on FLA/SLA. It is well established that personality plays an important role in the experience of anxiety (Rachman, 1998) as well as in interpersonal communication (Eynseck and Eynseck, 1979). For example, extroverts tend to be sociable, talkative, and verbally fluent, whereas introverts tend to be reserved, quiet, and unassertive (Eynseck and Eynseck, 1979; Goldberg, 1992). People high in emotional stability tend to be calm, relaxed, and display low levels of emotional arousal, even in stressful situations (Engles, 2009). Conversely, people low in emotional stability tend to experience negative emotions such as sadness, worry, and anxiety and to interpret situations as threatening (Poropat, 2009). 
Dewaele (2002) studied the link between extroversion, emotional stability, psychoticism and FLA in a group of 100 Flemish L2 learners. Students who scored higher in extroversion and psychoticism scored lower in FLA; emotional stability had no significant effect on FLA. MacIntyre and Charos (1996) similarly found no link between emotional stability and FLA among university French L2 learners. Although these findings support the independent nature of FLA and trait anxiety proposed by Horwitz et al. (1986), it is clearly of interest to further examine individual differences that influence the experience of SLA.

\section{The Present Study}

Dewaele et al.'s (2008) investigation provided important preliminary evidence that language anxiety extends to those who are no longer formal language learners and is evident across a variety of personal and professional contexts. The present study sought to extend this pioneering work by examining SLA among a large sample of adult Latin-American immigrants to Australia who exist permanently in an L2 environment. Similar to Dewaele et al. (2008), SLA was measured across different social contexts. In contrast to their study, participants were immigrants, were drawn from a wide variety of professional backgrounds (not just language-related) and had a range of levels of L2 proficiency.

Aims of the present study

The aims of our study were (1) to provide data regarding the existence and severity of SLA among L2 adult immigrants, and (2) to explore individual differences in

SLA. Specifically we were interested in the following research questions:

1. Does second language anxiety exist among adult immigrants?

2. How severe is second language anxiety among immigrants? 
3. To what extent is second language anxiety among adult immigrants related to demographic variables such as age, gender, and level of education?

4. What is the relationship between SLA and self-rated L2 competence?

5. To what extent is second language anxiety among adult immigrants related to personality variables such as extroversion/introversion and emotional stability/neuroticism?

\section{Hypotheses}

Based on the research explored above, it was predicted that:

a. Participants would report significantly more anxiety in their oral communication in English than in Spanish;

b. Based on Dewaele et al.'s (2008) findings regarding situational influences on SLA, participants would be equally anxious in L1 and L2 when speaking with friends, but significantly more anxious when speaking in L2 with strangers, at work, on the phone, and in public, all of which may be perceived as more threatening environments;

c. The findings would replicate Dewaele et al. (2008) in showing (1) no effects of gender, (2) no effects of level of education, and (3) a reduction of SLA with age;

d. Regarding the overall measure of SLA across all contexts, anxiety would be lower for participants who reported higher self-rated L2 competence; and

e. Participants higher in extroversion would present lower levels of SLA and that emotional stability would not have a significant effect on levels of SLA. 


\section{Method}

\section{Participants}

Participants were 219 Spanish-English bilinguals from Latin American countries (147 females and 72 males) aged 21 to 73 years $(M=39 ; S D=11.5)$ who spoke Spanish as their first and dominant language, were immigrants to Australia (i.e., not tourists, temporary workers or students, or L2 learners), and arrived in Australia at least one year prior to the commencement of the study, aged at least 20 years. Participants were recruited by snowball sampling (Hoyle, Harris, \& Judd, 2002); announcements were displayed in the Griffith Univeristy web site and online social media targeting Latin America groups (e.g., "Latinos en Australia"); and emails were sent to contacts of the author's social network. In addition, SLASA (Spanish and Latin American Association for Social Assistance) was contacted to advertise the survey and face-to-face contact was made with Latin American churches and soccer clubs. With regard to educational background, 9\% had Higher than University Degree, 65\% University Degree, 11\% Diploma, 7 \% Certificate, 7\% High School, and 1\% Primary School. Sixty nine percent of participants reported speaking Spanish at home, $28 \%$ English, $2 \%$ both. Ninety per cent of working participants spoke English at work, 3\% Spanish, and 7\% both while $86 \%$ spoke Spanish every day (mostly at home) and 14\% only weekly. Most participants rated themselves as having moderate to high proficiency in speaking (92\%), comprehending (92\%), reading (85\%), and writing (89\%) the L2. Participants' mean score in Emotional Stability was $32(\mathrm{SD}=7.32)$ and in Extroversion was $32.6(\mathrm{SD}=6.71)$. 


\section{Materials}

The survey comprised two questionnaires: the Bilingualism and Emotions Questionnaire (BEQ; Dewaele and Pavlenko, 2003) and the 50-Item Set of International Personality Item Pool Big-Five Factor Markers (IPIP-BFFM; International Personality Item Pool). As these instruments were originally developed in English they were translated into Spanish and back-translated to English following Noels, Pon and Clement's (1996) method to accommodate those respondents who could not read English or who preferred to answer in their first language.

\section{Demographic information}

Participants were asked a series of demographic questions including gender, age, country of birth, age at arrival in Australia, ethnic group, language spoken at home and at work, occupation, current city of residence, email address (optional), and educational level. Educational level was measured on a scale of 1 (primary school) to 6 (postgraduate studies).

\section{Language use}

To obtain background information on the use of L2 and L1, participants were asked 'How often do you speak English/Spanish?' and provided with the following options:1= Every Day, 2= Every Week, 3=Every Month.

\section{Bilingualism and Emotions Questionnaire (BEQ)}

The BEQ was developed by Dewaele and Pavlenko (2003) to investigate multilingualism in up to 5 languages. It contains 34 questions grouped in three parts related to background information (e.g., age, gender), linguistic information (e.g., selfrated language proficiency, frequency of use of each language) and language and 
emotions (e.g., feeling of anxiety, language preference expression of deepest feelings). A modified version of the BEQ was used for the present study to askparticipants about two languages (Spanish and English) instead of five languages as in the original (L1L5).

\section{Second language anxiety (SLA)}

This 5-item scale $(a=.91)$ was a closed question from the BEQ tapping into five different contexts where the L2 is used. The question read 'How Anxious are you when speaking in your L2 (English) with different people in different situations (a)with friends, (b) with strangers, (c) at work, (d) on the phone, (e) in public' ? Participants were provided with a response scale of one ("Not at all Anxious") to five ("Extremely Anxious"). This measure was used in two different ways: as individual measures of anxiety in each context (AnxietyFriends, AnxietyStrangers, AnxietyWork, AnxietyPhone, and AnxietyPublic; lowest possible score 1; highest possible score 5) and as a measure of total anxiety by adding the participants' scores in each context (TotalSLA; lowest possible score 5; highest possible score 25). In the present study, the alpha coefficient for this measure was .88 .

First language anxiety (FirstLA)

To measure anxiety in L1, the same question as for SLA was asked again using the same five point scale. Cronbach's alpha reported by Dewaele and Pavlenko (2003) for the five items was .88; in the present study alpha coefficient $=.79$.

\section{L2 self-perceived competence}

Self-report competence in English was measured through 5-point Likert scales from the BEQ ranging from 1 (minimal) to 5 (maximal). The question reads 'On the scale from 1 (least proficient) to 5 (fully proficient) how do you rate yourself in USING the English language? (a) speaking English, (b) reading English, (c) writing English, 
and (d) comprehending English.' As the focus in this study was on skills related to oral communication, a self-perceived competence score was obtained by adding speaking and comprehension scores (lowest possible score 2; highest possible score $10)$.

International Personality Item Pool Big-Five Factor Markers (IPIP - BFFM)

The 50-Item Set of IPIP -BFFM (International Personality Item Pool, 2012) was used to measure personality. These five scales contain 10 items each, labelled Extraversion, Agreeableness, Conscientiousness, Emotional Stability, and Intellect/Imagination, and particiants could score a minimum of 10 and a maximum of 50. The IPIP has reported the following alpha coefficients for each domain, Extraversion=.87 (In the present study $a=.82$ ); Emotional stability $=.84$ (In the present study $a=.84)$, Agreeableness $=.82 ;$ Conscientiousness $=.79 ;$ and Intellect $=$ .84. Although the whole inventory was administered to participants, only the Extroversion and Emotional Stability scale were used in this study. An item example for Extraversion is 'talk to a lot of different people at parties', and for Emotional Stability 'I am relaxed most of the time'.

\section{Procedure}

Data were collected by means of paper-and-pencil and online questionnaires, both methods being equivalent (Hoyle, Harris and Judd, 2012). The survey was advertised as “The Experience of Bilingualism in Australia: Examining Latino Immigrants' Attitudes to Speaking English as a Second Language". The measures were pilot tested among 12 Spanish-English bilinguals from the first author's social network who met the participation criteria. Its first page was printed in Spanish and included a welcome message, a brief description of the study, instructions on how to complete the survey, 
and a link to 'Consent and Information Page'. The second page had the option to choose Spanish or English as the survey language. The survey took between 25 and 30 minutes to complete. Completion of the questionnaire was anonymous and was not timed or supervised. All advertisements were published in Spanish and English following approval for the study from the university's Human Research Ethics Committee.

\section{Design}

A repeated measures design was used in this study. To compare levels of language anxiety in English and Spanish, all participants were assigned to both languge conditions and data was analysed using of Wilcoxon Signed Rank Tests. In addition, to investigate and compare variation in levels of SLA and First language anxiety (FirstLA) across the five contexts, repeated measures ANOVAs were conducted with SLA and FirstLA as the DV and Context as the IV (five levels: speaking with friends, speaking with strangers, on the phone, in public, and at work). The DVs were measured (a) as a total score calculated by adding the scores of the scale's five contexts, and (b) as individual scores on each of the five specific contexts. The relationship between participants' individual differences and SLA were investigated using simultaneous-entry multiple regression analyses with age, years of residency in Australia, education level, English proficiency, extraversion, and emotional stability as IVs and SLA as DV. Gender differences were analised using $t$ tests.

\section{Results}


All data were screened and analysed using Statistical Package for Social Sciences (SPSS). Surveys with missing data in relevant measures were discarded, leaving a total of 190 participants. From these 190 participants, 6 who did not complete the personality test were included only when the analysis did not pertain to the personality measures. Due to the online nature of this sample collection it was not possible to estimate response rates; however, there was a 50\% response rate from paper-andpencil surveys.

\section{Existence and Severity of SLA}

Frequencies of FirstLA and SLA scores reported by participants are displayed in Table 1, including percentages of endorsements of being Not at All Anxious to Extremely Anxious in all five contexts. In addition, to test the hypothesis that participants would experience higher levels of anxiety speaking their L2 than in their L1, scores of FirstLA and SLA were compared as a total and in each context. Due to severe violations of normality of FirstLA variable (with a majority of participants endorsing Not at All Anxious or A Little Anxious across the different contexts) nonparametric tests were used. A set of Wilcoxon Signed Rank Tests with Bonferroni correction $(p=.01)$ indicated significantly higher anxiety in L2 than L1 in general and individual contexts as shown in Table 2.

To investigate variation in levels of SLA across the five contexts, repeated measures ANOVAs were conducted. Scores in SLA measured for each individual context presented some degree of skewness (>+-3), except in the case of anxiety when speaking in public: however, it is known that ANOVA is robust to violations of normality, especially given large sample sizes (Howell, 2010). Since the assumption of sphericity was violated, the multivariate statistics are reported. Results indicated a 
significant variation in levels of anxiety depending on the context in which English was used; Wilks' Lambda $=.34, F(4,186)=89.95, p<.001$, multivariate $\eta_{p}{ }^{2}=.66$.

Follow up paired-samples $t$-tests using Bonferroni correction $(p=.005)$ were conducted. Speaking English with friends was significantly less anxiety provoking $(M=1.51, S D=.05)$ than speaking English with strangers $(M=2.10, S D=.08)$, $t(189)=-8.35, p<.001, d=-.61$; at work $(M=2.11, S D=.08), t(189)=-9.39, p$ $<.001, d=-.68$; on the phone $(M=2.5, S D=.09), t(189)=-12.84, p<.001, d=-$ .93 ; or in public $(M=3.00, S D=.09), t(189)=18.67, p<.001, d=-1.35$. Although anxiety experienced while speaking English with strangers was not significantly different to anxiety experienced when speaking English at work, it was significantly lower than speaking English on the phone, $t(189)=6.45, p<.001, d=-.47$; or in public, $t(189)=-12.40, p<.001, d=-.90$. Anxiety experienced when speaking English at work was significantly lower than speaking English on the phone, $t(189)=$ $-5.96, p<.001, d=-.43$ or in public, $t(189)=-11.75, p<.001, d=-.85$. Speaking English on the phone was less anxiety provoking that speaking English in public, $t(189)=-7.00, p=<.001, d=-.50$. In summary, results showed that speaking English with friends was the least anxiety provoking activity and speaking English in public was the most anxiety provoking activity.

\section{Individual differences in SLA}

The relationship between SLA and gender was investigated using a between-groups $t$ test. There were no significant differences in Total SLA score between females $(M=$ 11.51, $\mathrm{SD}=4.47)$ and males $(M=10.70, S D=4.41), t(188)=1.18, p=.241, \mathrm{n}^{2}=$ .007 . 
The relations between SLA and age, years of residency in Australia, education level, English proficiency, extraversion, and emotional stability were investigated using simultaneous-entry multiple regression analyses. An evaluation of the specific assumptions of regression indicated that heteroscedasticity, linearity, and normality of residuals were violated but were later achieved by square root (sqrt) transformation of the following variables: Total SLA, anxiety speaking with friends, anxiety speaking with strangers, and anxiety speaking at work (Howell, 2010).

\section{Individual differences in Total SLA}

A simultaneous-entry multiple regression was performed including the following independent variables: age, years of residency in Australia, education level, English proficiency, extraversion and emotional stability. Table 3 displays zero-order correlations between all variables.

Results of the regression indicated that the model explained $49 \%$ of the variance in Total SLA, $R^{2}=.49[.39, .59], F(6,177)=28.70, p<.001$. Three variables emerged as significant, unique predictors of Total SLA; of these, English competence was the strongest predictor of Total SLA, followed by age, and extroversion. Specifically, Total SLA was lower among participants with higher English competence, as well as older participants, and those who were more extraverted. Table 4 displays the unstandardized regression coefficients (B), intercept, the standardized regression coefficients $(\beta)$, the semi partial correlations $\left(\mathrm{sr}^{2}\right), \mathrm{R}^{2}$, and adjusted $\mathrm{R}^{2}$, means, and standard deviations. 
A set of independent-samples $t$-tests was performed to compare the SLA scores for females and males in each of the five contexts of interest and found no gender differences in SLA in any of the five contexts; $t$ 's $(135,55) \leq 1.50, p$ 's $\geq .13, d$ 's $\leq .011$.

Next, simultaneous-entry regression analysis (using the aforementioned predictors) was conducted to investigate SLA predictors in each individual context. The overall result indicated that only English competence was a strong predictor of SLA across all contexts and that extroversion and age were significant in some contexts. All remaining IVs did not predict SLA. Table 5 displays correlations between IVs and SLA in each context whereas Tables 6 to 10 show detailed regression statistics for each context including the $\mathrm{B}$ values, intercept, $\beta$ values, $\mathrm{sr}^{2}$, $R^{2}$, and adjusted $R^{2}$.

When individually applied to speaking with friends, speaking at work, and speaking in public the regression model explained $35 \%$ of the variance in SLA, $R^{2}=$ $.35[.24, .46], F(6,177)=16.00, p<.001 ; 33 \%$ of the variance, $R^{2}=.33[.22, .44], F$ $(6,177)=15.00, p<.001 ;$ and $38 \%$ of the variance, $R^{2}=.38[.27, .49], F(6,177)=$ $17.84, p<.001$, respectively. English competence was the strongest predictor of SLA followed by extroversion (both negative relations) in these three contexts.

When applied to speaking with strangers and speaking on the phone the regression model explained $31 \%$ of the variance, $R^{2}=.31[.20, .42], F(6,177)=$ $13.50, p<.001$, and $41 \%$ of the variance, $R^{2}=.41[.31, .51], F(6,177)=20.52, p<$ .001 , respectively. English competence was the strongest predictor of SLA followed by age (both negative relations) in both contexts. 


\section{Discussion}

Despite anecdotal and clinical evidence that adult immigrants may suffer from anxiety specifically related to communicating in their less dominant language for everyday interactions, to date, there has been very little research on the topic of SLA among immigrants. Therefore, the aims of this study were to investigate the existence and severity of SLA among adult immigrants from Latin America to Australia and to explore individual differences in SLA.

Over half of the sample reported at least moderate anxiety in L2 contexts, providing clear support for the presence of SLA in adult immigrants. These findings are consistent with those reported by Dewaele et al.(2008) on adults L2 users and provide empirical support to previous anecdotal and clinical reports of SLA in bilingual immigrants (e.g., Imberty, 2006; Perez-Firmat, 2003). Importantly, participants in this study consistently reported more anxiety in their oral communication in English (L2) than in Spanish (L1) indicating that their anxiety was specifically associated with communicating in their less dominant language (Horwitz, 2010; Dewaele et al, 2008).

SLA was found to vary significantly across social contexts, with Speaking with friends, with strangers, at work, on the phone, and in public rated as progressively more anxiety provoking. In general, this pattern of findings is consistent with research on second language learning regarding the effects of the situation (e.g., formality, interlocutor, topic of conversation) on SLA. As the L2 user perceives situations to be progressively internally or externally more threatening, anxiety increases (Daly, 1991; Pappamihiel, 2006; Spielberg, 1972). Specifically, participants felt the least anxious while speaking with their friends. In contrast, speaking in public was the most anxiety provoking L2 interaction. In addition to 
having to formulate and convey ideas to an audience, bilingual individuals are concerned with making public any linguistic weakness (Gregersen, 2003).

The absence of a significant difference in levels of SLA speaking at work and speaking with strangers suggests that using the L2 in these two contexts may be similarly anxiety provoking since any error could have practical consequences such as the potential loss of professional image or inability to make a good first impression. Finally, speaking on the phone may be challenging for bilinguals due to having to produce spontaneous unprepared speech and the absence of nonverbal cues to compensate for potential limitation in L2 comprehension.

Participants reported that they were significantly more anxious when speaking English (L2) than Spanish (L1) in all five social contexts. In contrast, Dewaele and colleagues (2008) found no difference in levels of anxiety in L1 and L2 when speaking with friends. This discrepancy could be due to differences between the characteristics of the two studies' samples. It is unclear whether Dewaele et al.'s participants were immigrants or bilinguals living in their own countries, in which case, it may be that the participants' L2 may not have been the majority language or/and the interlocutor may have been using their L2 as well. Conversely, permanent bilinguals are likely to have local native speakers as friends. In such cases, in spite of the friendship and confidence, the language 'inequality' still remains. Speaking to native speakers has been found to be particularly anxiety provoking for speakers in L2 environments in several studies (Bigdali, 2007; Rose, 2008; Woodrow, 2006).

Overall, these results indicated that SLA is pervasive in adult immigrants, who are burdened with moderate to very high levels of anxiety associated with dependence on their less dominant language for most transactions on a daily basis. 
Second language anxiety may affect most facets of the bilingual life from public, professional, and social relationships to private interactions with friends.

\section{Individual differences in SLA}

Consistent with previous findings (Dewaele, 2007; Dewaele et al., 2008), there were no effects of gender and education level on total SLA. In constrast, older immigrants (independently of the time they had spent in Australia) tended to be less anxious when speaking English relative to younger immigrants. Arguably, as people grow older, their anxiety related to social evaluation tends to decrease (Brener, 2005) consistent with the age-related positivity effect which suggests that people generally focus more on the positives and worry less as they grow older (Carstensen and Mikels, 2005).

The strongest predictor of SLA was self-perceived L2 competence. Immigrants who perceived themselves as less competent to communicate in English clearly experienced more anxiety when doing so. This negative relationship between SLA and self-perceived L2 competence has been repeatedly reported in foreign and second language anxiety research (e.g., Dewaele, 2008; Donovan and MacIntyre, 2005). Although self-perceived L2 competence correlates highly with actual competence (Noels and Clement, 1996), it is important to recognize the potential of SLA to bias self-perceived competence in a negative direction. Bilinguals who doubt their linguistic competence may become anxious when using their L2 and bilinguals who are anxious about using their L2 may underestimate their competence (MacIntyre, 1997). However, as only self-reported language proficiency was examined in this study, it is not possible to establish how accurate these selfperceived competence reports are nor the potential effect of SLA on self-perception 
of competence. Future research may usefully investigate this relationship further by including a linguistic measure of L2 oral competence (e.g., naturalistic observations, oral interviews).

As Bandura (1982) has argued, it is a person's perception of control that influences choices and behaviours. It is likely therefore that it is still the L2 immigrant's beliefs about his/her capacity to communicate in the L2, rather than actual L2 competence, that are more likely to influence and determine his/her behaviour towards L2 interactions. As a result of these beliefs, bilinguals may avoid anxiety provoking situations and instead be limited in their social life, employment, education, and career progress. For example, a perceived lack of proficiency in the L2 may prevent immigrants from applying for a job that they may be well equipped for. Thus, in everyday life, self-perceived competence may have more potential to influence choices and decisions involving interactions in the L2 than the actual proficiency.

Similar to findings reported byDewaele's (2002), there was evidence of personality differences contributing to SLAwith introverts, who tend to be less fluent verbally, more reserved, and less assertive in social interactions (Eysenck and Eysenck, 1979) more at risk of experiencing higher levels of SLA than their more sociable, outgoing, outspoken counterparts. In regards to emotional stability, the results showed a weak but significant negative association with SLA; however, in the context of all the other predictors the relationship was no longer significant. These results are consistent with Dewaele's (2002) and MacIntyre and Charos' (1996) who found that emotional stability was not a significant predictor of SLA. Thus, whether someone tends to be calm and emotionally stable or whether he/she tends to interpret situations as threatening and to be generally anxious does not explain SLA. This 
finding is consistent with Horwitz et al.'s (1986) theory that it is the social and communicative demands of the L2 interaction and not the predisposition to anxiety, which drives SLA.

Interestingly, the influence of extraversion and age varied across contexts. Older L2 immigrants were significantly less anxious than their younger counterparts when speaking English on the phone and with strangers, and extroverts were less anxious when speaking with friends, at work, and in public.

\section{Conclusions}

As the world continues to become more interconnected with the progressive movement of immigrants from different language backgrounds, issues related to the emotional consequences of living in a second language are likely to increase. This is the first study, as far as we know, to investigate the existence and severity of SLA in adult L2 immigrants and the demographic, cognitive, and personality factors that predict SLA in this population. The results clearly demonstrate that SLA exists among adult L2 immigrants at moderate, high and very high levels permeating most aspects of their lives.

Therefore, these findings have important practical implications for professionals providing psychological care to permanent bilinguals and for educators and employers of L2 immigrants. Health practitioners who come in contact with bilingual clients need to be aware that SLA is in itself a source of specific anxiety which may obscure psychological assessment and treatment if it is overlooked or if its symptoms are misinterpreted. In addition, SLA may negatively interfere with the socialisation and oral communication of adult immigrants, (Woodrow, 2006) with further education and in the work place, to the detriment of the person's academic and job performance, and 
interaction with peers and clients. Future research may usefully investigate the relationship between self-perceived L2 competence and actual competence by including a linguistic measure of L2 oral competence. However it is clear that SLA is a problem that exerts an influence on more than the immediate and obvious domain of communication. Further research is also needed to investigate the extent that SLA may affect the person's self-concept, personal and social stability, psychological wellbeing, and the fulfilment of personal goals. 
References

Abu-Rabia, Salim. 2004. “Teacher's Role, Learner's Gender Differences, and FL Anxiety Among Seventh-grade Students Studying English as FL.” Educational Psychology: An International Journal of Experimental Educational Psychology 24: 711-721. doi:10.1080/0144341042000263006.

Bandura, Albert. 1982. "Self-efficacy Mechanism in Human Agency.” American Psychologist 37: 122-147.

Bialystok, Ellen. 2008. "Bilingualism: The Good, the Bad, and the Indifferent." Bilingualism: Language and cognition 12: 3-11.

Bigdali, Shoaleh. 2007. ESL Anxiety in Iranian Immigrant Women. PhD diss., Simon Graser University, (ISBN: 978-0-494-40997-8)

Brener, G. A. 2005. "Age Difference in the Presentation of Anxiety." Aging and Mental Health 10: 298-302. doi: 10.1080/136078605000409898.

Carstensen, Laura L., and Joseph Mikels. 2005. “At the Intersection of Emotion and Cognition: Aging and the Positivity Effect." Current Directions in Psychological Science 14: 117-121.

Ceroz, Jasone. 2008. "The Acquisition of Pragmatic Competence and Multilingualism in FL Contexts." In Intercultural Language use and Language Learning, edited by E. Alcon Soler, and M. P. Safant Jorda, 141-166. Spain: Springer.

Daly, J. 1991. “Anxiety and Second Language Learning: Toward a Theoretical Clarification.” In Language Anxiety: From Theory to Research to Classroom Implications, edited by E. Horwitz and D. Young, 3-13. New Jersey: PrenticeHall. 
Dewaele, Jean- Marc. 2002. "Psychological and Sociodemographic Correlates of Communicative Anxiety in L2 and L3 Production." International Journal of Bilingualism 6: 23-38.

Dewaele, Jean- Marc. 2007. "The Effect of Multilingualism, Sociobiographical, and Situational Factors on Communicative Anxiety and Foreign Language Anxiety of Mature Language Learners.” International Journal of Bilingualism 11: 391409.

Dewaele, Jean- Marc. 2008. "Interindividual Variation in Self-perceived Oral Proficiency of English L2 Users.” In Intercultural Language Use and Language Learning, edited by E. Alcon Soler, and M. P. Safant Jorda, 141166. Spain: Springer.

Dewaele, Jean- Marc, and Aneta Pavlenko. 2003. Web Questionnaire on Bilingualism and Emotion. University of London.

Dewaele, Jean- Marc, K. V. Petrides, and Adrian Furham. 2008. "Effects of Trait emotional Intelligence and Sociobiographical Variables on Communicative Anxiety and Foreign Language Anxiety Among Adult Multilinguals: A Review and Empirical Investigation.” Language Learning 58: 911-960. Dewaele, Jean- Marc, and Pieter Oudenhoven. 2010. "The effect of multilingualism and multiculturalism on personality: No Gain Without Pain for Third Culture Kids?" International Journal of Multilingualism 6: 443-259.

Dewaele, Jean-Marc, and Peter D. MacIntyre. 2014. “The Two Faces of Janus? Anxiety and Enjoyment in the Foreign Language Classroom.” Studies in Second Language Learning and Teaching 4: 237-274. doi:

10.14746/ssllt.2014.4.2.5. 
De Zuleta, Felicity. 1990. "Bilingualism and Family Therapy.” Journal of Family Therapy 12: 255-265.

Donovan, Leslie, and Peter. D. MacIntyre. 2005. “Age and Sex Differences in Willingness to Communicate: Communication Apprehension and Selfperceived Competence.” Communication Research reports 21: 220-227.

Engler, Barbara. 2009. Personality theories. ( $8^{\text {th }}$ ed.). Australia: Wadsworth.

Eysenck, Michael, and Christine Eysenck. 1979. "Memory Scanning, IntroversionExtroversion, and Levels of Processing." Journal of Research in Personality 13: 305-315.

Goldberg, Lewis. 1992. “The Development of Markers for the Big-Five Factor Structure.” Psychological Assessment 4: 26-42.

Gregersen, T. S. 2003. “To Err is Human: A Reminder to Teachers of Languageanxious Students.” Foreign Language Annals 36: 25-32. doi: 10.1111/j.19449720.2003.tb01929.x.

Griffith, James, and Sandra Villavicencio. 1985. "Relationship Among Acculturation: Sociodemographic Characteristics and Social Support in Mexican-American Adults." Hispanic Journal of Behavioural Sciences 77: 75-92.

Grosjean, Francois. 1982. Life With Two Languages: An Introduction to Bilingualism. USA: Harvard University Press.

Horwitz, Elaine. 2001. "Language Anxiety and Achievement." Annual Review of Applied Linguistics 21: 112-126.

Horwitz, Elaine. 2010. "Foreign and Second Language Anxiety.” Language Teaching 43: 154-167.

Horwitz, Elaine, Michael Horwitz, and Joann Cope. 1986. "Foreign Language Classroom Anxiety." The Modern Language journal 70: 125-132. 
Howell, David. 2010. Statistical Methods for Psychology $\left(8^{\text {th }}\right.$ ed.). Australia: Wadsworth Cengage Learning.

Hoyle, Rick, Monica Harris, and Charles Judd. 2002. Research Methodss in Social Relations. ( $7^{\text {th }}$ ed.). USA: Wadsworth Thomson Learning.

Imberty, Priska. 2007. "Who Resides Behind the Word? Exploring and Understanding the Language Experience of the Non-English-speaking Immigrant." Journal of Contemporary Social Services 88: 67-73.

International Personality Item Pool: A Scientific Collaboration for the Development of Advanced Measures of Personality Traits and Other Individual Differences. [Internet Web Site]. Retrieved from http://ipip.ori.org/

Jones Diaz, Criss. 2003. "Latino/a Voices in Australia: Negotiating Bilingual Identity." Contemporary issues in Early Childhood 3: 314-336.

MacIntyre, Peter D. 1995. "How does Anxiety Affect Second Language Learning? A Reply to Sparks and Ganschow." The Modern Language Journal 79: 90-99. MacIntyre, Peter D., Zoltan Dornyei, Richard Clement, and Kimberly Noels. 1998. “Conceptualizing Willingness to Communicate in L2: A Situational Model of L2 Confidence and Affiliation.” The Modern Language Journal 82: 545-562. MacIntyre P.D., and Robert C. Gardner. 1991. “Anxiety and Second Language Learning: Toward a Theoretical Clarification.” In Language Anxiety: From Theory to Research to Classroom Implications, edited by E. Horwitz and D. Young, 41-53. New Jersey: Prentice-Hall.

MacIntyre, P. D., Kimberly Noels, and Richard Clement. 1997. "Biases of Self- rating of Second Language Proficiency: The Role of Language Anxiety." Language Learning 44: 283-305. 
McCrosky, James, and Linda McCrosky. 1988. "Self-report as an Approach to Measuring Communication Competence." Communication Research Reports 5: 106-113.

Noels, Kimberly, Gordon Pon, and Richard Clement. 1996. "Language, Identity and Adjustment: The Role of Linguistic Self-perception in the Acculturation Process." Journal of Language and Social Psychology 15: 246-63.

Onwuegbuzie, A. J., Bailey, P., and Daley, C. 1999. "Factors Associated with Foreign Language Anxiety." Applied Psycholinguistics 20: 217-239.

Doi: $10.1017 / \mathrm{S} 0142716499002039$

Pappamihiel, N. E. 2001. "Moving from the ESL Classroom into the Mainstream: An Investigation of English Language Anxiety in Mexican Girls.” Bilingual Research Journal 25: 31-39. doi: 10.1080/15235882.2001.10162783.

Pavlenko, A. 2006. Bilingual minds: Emotional Experience, Expression, and Representation. Canada: Multilingual Matters. doi: 1017/S0272263107070519. Perez-Firmat, Gustavo. 2003. Tongue Ties: Logo Eroticism in Anglo-Hispanic Literature. USA: Palgraven Macmillan.

Poropat, A. E. 2009. “A meta-analysis of the Five-factor Model of Personality and Academic Performance.” Psychological Bulletin 135: 322-338. doi: 10.1037/a0014996.

Rachman, S. (1998). Anxiety. Canada: Psychology Press.

Rose, Glenda. 2008. Language Acculturation Anxiety in Spanish Apeaking Adult Immigrants Learning English in the United States. PhD diss., University of Texas. Available from ProQuest Dissertations and Theses database. (UMI No. $3315370)$. 
Spielberger, Charles. 1972. Anxiety: Current Trends in Theory and Research. NY: Academic Press.

Steinberg, Faith, and Elaine Horwitz. 1986. "The Effects of Induced Anxiety on the Denotative and Interpretative Content of Second Language Speech.” TESOL Quarterly 20: 131-136.

Tran, Thi. 2012. "A Review of Horwitz, Horwitz and Cope's Theory of Foreign Language Anxiety and the Challenges to the Theory." English Language Teaching 5: 69-75.

Woodrow, L. 2006. “Anxiety and Speaking English as a Second Language.” RELC Journal 37: 308-328. doi: 10.1177/0033688206071315.

Zhang, Renxia, and Jian Zhong. 2012. "The Hindrance of Doubt: Causes of Language Anxiety." International Journal of English Linguistics 2: 27-33 